\title{
How "Gendered" Are Gendered Pathways into Prison?: a Latent Class Analysis of the Life Experiences of Male and Female Prisoners in The Netherlands
}

\author{
Katharina J. Joosen ${ }^{1} \cdot$ Hanneke Palmen ${ }^{2}$. \\ Candace Kruttschnitt ${ }^{3}$. Catrien Bijleveld ${ }^{1}$. \\ Anja Dirkzwager ${ }^{1} \cdot$ Paul Nieuwbeerta ${ }^{2}$
}

Received: 12 February 2016 / Revised: 28 April 2016 / Accepted: 3 May 2016 /

Published online: 14 May 2016

(C) Springer International Publishing AG 2016

\begin{abstract}
Purpose Studies of pathways to offending have mainly focused on identifying either gendered trajectories in criminal careers, gendered risk factors for offending, or gendered pathways. Less common is research that explores to what extent classes or types of pathways to offending are actually gendered. In the current study, we examine latent classes of pathways to prison for both males and females in The Netherlands using two large samples and a broad array of background characteristics.

Methods Data on male pathways were derived from the Prison Project that includes data on 1904 male prisoners, while data on female pathways were derived from the VIP study that includes 397 women. The data cover the following domains: age of onset, offense type, family situation in childhood, substance use, homelessness, economic marginalization, mental health, romantic relationships, and parenthood.

Results For both the male and female prisoners, we found the following four comparable typologies: (a) multi-problem property offenders, (b) multi-problem violent offenders, (c) drug-connected offenders, and (d) low-risk-exposure offenders. The male low-risk category could be further divided into a low-risk group of property offenders and a low-risk group of violent offenders, resulting in a five-class solution.

Conclusion Subgroups characterized by background characteristics of male and female prisoners show remarkable similarity. Results indicate that prison re-entry programs
\end{abstract}

Katharina J. Joosen

kjoosen@nscr.nl

1 Netherlands Institute for the Study of Crime and Law Enforcement, P.O. Box 71304, 1008

BH Amsterdam, The Netherlands

2 Institute for Criminal Law and Criminology, Leiden University, Leiden, Netherlands

3 Department of Sociology, University of Toronto, Toronto, ON, Canada 
should pay attention to risk exposure prior to incarceration. In so doing, interventions can be tailored to the risk domains shared across genders.

Keywords Gendered pathways · Life experiences · Latent class analyses · Male and female prisoners . The Netherlands

\section{Introduction}

Internationally, the topic of gendered pathways to offending has been studied from different methodological perspectives. Generally, these studies fall into four categories. First, within the domain of criminal career trajectories, gendered pathways are explored by examining whether there are gender differences in the age of onset of offending and its impact on the development of problem behaviors and/or criminal careers (e.g., [53]). A second strain of pathways research uses structural equation modeling, or other types of path analysis, to investigate gendered or female-specific pathways to antisocial behavior and offending (e.g., [11]). A third group of studies investigates the occurrence, and/or impact on the risk for offending, of one or multiple potentially criminogenic experiences during the life course of male and female prisoners (i.e., risk factor approach; e.g., [33, 41]). Fourth, some studies also investigate whether typologies or subgroups of male and female offenders are gendered based on background variables and exposure to criminogenic factors during the life course (e.g., [16]). Taken together, the existing studies on typologies or subgroups have targeted (a) adolescent delinquent samples [6, 21, 61, 64], (b) male-only samples [4], (c) female-only samples [5, 7], (d) defining criminal activity or profiles $[23,24]$, or (e) a limited array of background characteristics [62].

What is still lacking from the international scientific landscape are comparisons of gendered pathways or life experiences prior to imprisonment among adult male and female prisoners across a broad array of similar criminogenic factors. In the current study, we investigate this by assessing whether typologies based on male and female prisoners' background characteristics are indeed gender-specific. We use two large subsamples of male and female prisoners in The Netherlands, and we investigate a broad array of risk factors. Apart from adding to our knowledge on gendered pathways into crime, our findings have practical relevance. Risk factors such as extensive criminal histories, drug abuse, low educational levels, and a lack of housing and employment predict recidivism after incarceration across gender (e.g., [14, 16, 27 , $39,43])$. While it is assumed that male and female offenders have different needs that can be tailored to by different re-entry programs [55, 60], it may be more appropriate to adjust and design such programs to match the specific needs of various types of prisoners regardless of their gender.

\section{Gendered Pathways to Offending}

During the 1990s, feminist scholars formulated a paradigm on gendered pathways to offending in a critical response to the lack of generalizability of existing male-oriented theories on crime. Daly [17] originally defined the concept of Gendered Pathways to Lawbreaking as an area of study focusing on the life events and experiences leading to 
offending and desistance among men and women. A central concept of this paradigm is the idea of blurred boundaries: when girls' responses to experiences of victimization both in childhood and adulthood become criminalized, leading to a complex relationship between victimization and offending (see [47]). However, this complex relationship between victimization and offending is also found among boys and men (for a review, see [28]). For example, childhood victimization is a significant marker for antisocial behavior among both boys and girls, even though processes through which child abuse portends offending can be gender-specific [36, 37]. In addition to childhood victimization, both gendered pathways and life course research focus on the prevalence and impact of a broad array of life experiences across gender such as age of onset; offending history; parental deviance; adulthood victimization; mental health problems; substance abuse; homelessness; economic marginalization; and relationships with peers, partners, and children (e.g., [2, 10, 19, 33, 40, 48]). However, studies of life histories prior to incarceration are rarely conducted with male samples. In general, pathways to prison studies, which do incorporate both a male and female subsample and investigate a broad domain of life experiences (e.g., [33, 41]), have reported prevalence rates and investigated the impact of these factors on the risk of offending (i.e., risk factor approach). Thus, overall, these studies have not compared whether risk factor exposure and background characteristics of male and female prisoners can be clustered into similar or gendered typologies.

\section{Existing Studies Defining Typologies or Subgroups of Male and Female Offenders}

In using typologies, subgroups of offenders or prisoners are differentiated based on background variables and exposure to criminogenic factors during their life course. Using qualitative methods, Daly's [16] seminal study on male and female pathways to felony court described a set of gendered typologies based on pre-sentence investigation reports. She divided the females into five categories. Street women were typically abused in childhood and ran away from home to end up living on the streets. They often developed a drug habit, which they would support by prostitution, theft, and drug dealing. Harmed-and-harming women also grew up in abusive and chaotic family situations resulting in violent outbursts, which were related either to drugs and alcohol or to the inability to cope with life circumstances. Drug-connected women were selling or using drugs in connection with partners or family members. Battered women ended up in court because of their violent retaliations directed at abusive partners. Lastly, the category of other women consisted of women who did not fit the other four profiles and whose crimes seemed to be economically motivated. Daly [16] found that the male offenders exhibited three similar pathways to those of the female offenders: street men, harmed-and-harming men, and drug-connected men. Additionally, she described a category labeled Costs and excesses of masculinity, with subgroups of violently explosive men, bad luck men, and men for whom street crime was more of a recreational activity with friends. Moreover, Daly gave gendered definitions of her labels street women and street men: while street women are characterized by running away from abusive homes, street men are characterized more by problems in school or drug use in adolescence.

More recently, some scholars have used a quantitative approach to examine the female typologies described by Daly. For example, Simpson et al. [57] defined six 
separate pathways or typologies of female prisoners using factor analysis. Even though these six pathways covered all of Daly's original five typologies of female detainees, the variables characterizing Daly's street women were spread over two distinct factors. Another recent study revealed eight different paths among incarcerated women (e.g., [5]). These eight paths were divided into four overarching typologies namely, (a) normally functioning but drug-abusing women, (b) battered women, (c) socialized subcultural pathways with less victimization and few mental health problems, and (d) aggressive antisocial women. Unfortunately, neither of these studies examines incarcerated men as well.

While less common than the work on female offenders, typologies of male offenders were explored in a recent study on 411 adolescent boys [4]. Data from the Cambridge Study in Delinquent Development was used to define clusters based on behavioral, social, and psychological characteristics, such as offending, IQ, impulsivity, sociability, delinquent friends, school, drug use, teen pregnancies, and parental bonds. A latent class analysis resulted in four distinct typologies of adolescent male offenders: least troubled, low achievers, impulsive rowdies, and ensnared partiers. The first and largest cluster of least troubled boys was a subgroup of minimal risk exposure combined with an absence of childhood and violent offending. The low achievers had the highest percentage of boys with low IQ, and all of these boys had left school early. The impulsive rowdies had low rates of violent offending, but they had the highest proportion of males with aggressive attitudes, impulsivity, and delinquent friends. Finally, boys in the ensnared partiers category were most likely violent offenders and had a history of childhood offending. In addition, these boys were most likely to be habitual drug users and to have weak parental bonds.

While the previously noted studies are important additions to the pathway scholarship, they focus solely on either male or female offenders. Comparing these studies, in an effort to determine whether there are gendered pathways to prison, is complicated by the fact that different variables are included for men and women. Nonetheless, for her dissertation, Daggett [14] did investigate gendered pathways based on pre-incarceration backgrounds of male and female prisoners and found three comparable typologies across gender namely, (a) street men and women, (b) situational offenders, and (c) drug-connected offenders. The street men and women both reported experiences with childhood abuse, parental substance abuse, juvenile delinquency, prior arrests, drug use, and mental health problems. The male and female situational offenders were characterized by employment, high school education, and marriage, while the drug-connected offenders typically reported prior arrests, drug offenses, and drug use. In addition, Daggett also defined two gender-specific typologies, namely a male chronic offender type and a female typology of first timers.

Furthermore, two recent studies of juvenile offenders, which included both genders, also found substantial overlap in the typologies of males and females consistent with Daly's [16] findings. Jones et al. [30] employed proximity scaling (i.e., the translation of a multivariate structure of relationships among variables into a geometric visual space) on their sample of 1838 juveniles. They found a traditional antisocial solution for both the boys and the girls, which was defined across gender by the following: defiance of parental authority, substance abuse, 
manifestations of violence, previous juvenile delinquency and felony complaints, inadequate parental supervision, and court findings of child neglect. An Australian study of 1503 convicted juveniles in the age range of 17 to 26 also analyzed classes based on offending type and official reports of childhood maltreatment. Results showed overlapping classes for males and females defined as (a) violent/ versatile, (b) nonviolent, and (c) low-level violent. In addition, among the males, a class of sexual offenders was found that did not exist for the female juveniles [21]. Summarily, these different studies investigating gendered pathways to offending and incarceration have not only shed light on the gendered nature of offending but, in so doing, have also highlighted the existence of substantial overlap between the typologies of male and female offenders.

\section{The Current Study}

In The Netherlands, female inmates comprised $8.2 \%$ of the total prison population in 2014: a percentage in line with the majority of countries worldwide where women constitute between 2 and $9 \%$ of all prisoners [9, 63]. Females detained in Dutch prisons report numerous negative life experiences including lack of stable housing, violent relationships with deviant partners, financial difficulties, substance abuse, and mental health problems [31]. Following the international trend in studies of gendered pathways (for a review, see [36, 38]), Dutch researchers are increasingly investigating the life histories, criminal trajectories, and carceral experiences of female offenders (e.g., $[3,31,58])$. In the current study, we examine the following research questions:

- Which typologies of both male and female prisoners in The Netherlands can be distinguished when examining background characteristics and life experiences prior incarceration, and to what degree are these male and female typologies comparable or gender-specific?

The data that we use cover a broad array of factors, namely the following: age of onset, offense type, family situation in childhood, substance use, homelessness, economic marginalization, mental health problems, romantic relationships, and parenthood. This study contributes to the important research on the question of whether there are gender-specific pathways to prison by investigating latent classes based on a broad array of risk factors using two large subsamples of both male and female prisoners.

\section{Methods}

\section{Sample}

The current study is based on male and female samples that originate from two different studies conducted in The Netherlands. The all-male sample of the Prison Project was used to determine male inmate latent classes, while the same analysis was run on the all-female sample from the VIP study (Vrouwen In Penitentiaire inrichtingen [Women in Prison]) to determine latent classes of female inmates. 


\section{The Prison Project ${ }^{l}$}

This project is a large-scale nationwide longitudinal study on intended and unintended effects of male imprisonment in The Netherlands [18]. From the 3983 individuals who entered one of the 32 Dutch pre-trial detention facilities between October 2010 and March 2011 and who met our selection criteria (male, aged 18-65 years, and born in The Netherlands), 2841 detainees were approached and informed of the study (71 \%). The majority of detainees who could not be approached had already been released. Of those approached, $1904(67 \%)$ participated in the study. ${ }^{2}$ The first wave of data collection is used in the current study in which a structured computer-assisted personal interview (CAPI) was administered. This wave of data collection focused on men's lives before imprisonment. Registered data of the Dutch Prison Service revealed no significant differences between those participating in the first wave of the Prison Project and those refusing to participate regarding their age and marital status. However, compared with refusers, participants were less likely to have been arrested for a property crime (30.7 versus $36.2 \%$; $\chi^{2}(3)=11.14, p<0.05$; [1]). Compared to the female sample, all male respondents were born in The Netherlands, and all recently entered a pre-trial detention center (data collection took place about 3 weeks after entering the detention facility). At the time of their interviews the total sample of men had a mean age of 30.3 years $(S D=10.7$, range 18-65).

\section{The VIP Study ${ }^{3}$}

The female sample was part of a Dutch study that investigated the lives of incarcerated women in The Netherlands (see [31]). During the period from June 2012 to September 2013 (newly), incarcerated women across each of the four Dutch female prison sites were personally approached and asked to participate in the study, which resulted in a response rate of $80.3 \%$. Women who did not want to participate mainly stated that they did not want to talk about their lives, did not have time, or had too much on their minds. Of the 512 women who initially agreed to participate, a total of 397 women were interviewed during their time in prison. Most of the 115 women, who agreed to participate but were not interviewed, had already been released from prison before the interview could take place (due to short sentences, longer but ending sentences, or transferals to different sites). ${ }^{4}$ At the time of their interview, the total sample of women had a mean age of 34.5 years $(S D=10.6$, range 18-70). Sixty-eight percent of the women had been convicted, while the other $32 \%$ were in pre-trial detention. As the female prisoners could be serving a sentence for minor (i.e., unpaid fines) or more serious offenses (i.e., murder), there is no reason to assume that the female (convicted) sample would only contain serious offenders. Contrary to the male sample, $58 \%$ of the female participants were born in The Netherlands: $13.4 \%$ was born in South America; $13.1 \%$ in the Caribbean; $11.3 \%$ in other European countries; and $4.2 \%$ in either Africa, North America, or Australia.

\footnotetext{
${ }^{1}$ Principal investigators: Prof. Paul Nieuwbeerta and dr. Anja Dirkzwager

${ }^{2}$ Eighty-five percent from the male sample was eventually sentenced with a term of imprisonment [65]

${ }^{3}$ Principal investigators: Prof. Candace Kruttschnitt and Prof. Catrien Bijleveld

${ }^{4}$ Unfortunately, official data on non-responders from the Dutch Prison Service was not available for the women.
} 


\section{Procedure}

Across both studies, trained research assistants approached participants personally. Potential participants received information on the aim and importance of the study, and they were told that participation was voluntary and the decision not to participate would have no effect on their trial, sentence, or treatment in prison. Prior to the start of the interviews, consent forms were signed, which emphasized confidentiality of the data and the right to withdraw participation at any time during or after the interview. Interviews took place in private settings without the presence of guards or other prison staff. Both studies used a computer-assisted personal interview (CAPI) to collect the data; the instrument designed specifically for the Prison Project was adapted for use in the VIP study. All female respondents received compensation for their interview in the form of a phone card with a value of 5 euros for their participation. Prison Service decided that male respondents were not allowed to receive compensation for participation in the Prison Project. The Ethics Committee of the Faculty of Law (CERCO) of the VU University Amsterdam approved both the Prison Project and the VIP study design, including interviewer protocols.

\section{Variables}

A total of 16 variables were included in the analyses covering the following broad domains: age of onset, type of offense, caregiver situation in childhood, work and income, living situation, partner relationships, substance (ab)use, mental health, and parenthood. All categorical variables were recoded into dichotomous variables, and continuous variables were split at a selected cutoff (i.e., for variable early starter) prior to entry in the analysis. Variables were chosen to cover the domains that have been investigated across previous studies on gendered pathways into prison for male and female prisoners (e.g., [5, 33, 42, 57]) and were available and measured in a similar manner for both the male and female datasets. Unfortunately, (comparable) measures of childhood victimization and relationship quality were not available.

For age of onset, the cutoff of prior age 18 was chosen for two reasons: (a) in The Netherlands, 18 is the minimum age for adult detention and (b) too few women self-reported a younger age of first offense when lower cutoffs were used. Caregiver situation in childhood was measured by (a) a composite of parental deviance consisting of parental alcohol and/or drug abuse, arrest, conviction, and/or incarceration between the respondents' age of 12 and 16 years old and (b) a measure of running away from home prior age 16 . Work and income were measured by three dichotomous variables on unemployment, debts, and the receipt of state benefits at the time of arrest. Living situation was measured by a dichotomous variable on homelessness at the time of arrest. Partner relationships were measured dichotomously as any steady relationship (i.e., including cohabitation or marriage) in the year prior arrest with a minimum duration of 3 months. Substance abuse was operationalized by asking (a) whether respondents used any type of drugs prior age 16, (b) whether they used soft drugs in the year prior arrest, and (c) whether they used hard drugs in the year prior arrest. Mental health was measured by a dichotomous composite on whether they had received any mental health treatment for any of the following problems in the year prior arrest: depression, anxiety disorder or phobia, alcohol addiction, drug addiction, ADHD, 
psychotic disorder such as schizophrenia, personality disorder, or any other emotional or psychological problem. The measure of parenthood indicates if they reported having any children (regardless of daily child care). Table 1 presents an overview of the variables included in the analyses with percentages within categories of gender. All data was self-reported for the women, while for the men, official data were used for the following variables: (a) type of current offense and (b) early starter. For the men, the registered data were used for analyses to minimize the number of missing values (in the VIP study, there was no access to criminal records of participants).

\section{Analysis}

First separate chi-square tests were run to examine potential gender differences on the variables included in the analyses. The odds ratios are also presented for the risk estimates per variable. Second, we conducted a latent class analysis (LCA) by using the mixture modeling command in Mplus version 7.3 ([51]-2010). This type of personcentered analysis ${ }^{5}$ is designed to identify classes or subgroups within the data by detecting underlying structures or clusters of individuals based on the included observed variables: in other words, it identifies typologies based on background characteristics and risk factor exposure [50]. The first parameters estimated with a LCA are the latent class probabilities; they describe the distribution of the classes and the class sizes. Second, in case of binary variables, the conditional probabilities describe the probability that a respondent in a particular class will have a score of 1 on a particular variable. Therefore, these conditional probabilities serve to interpret the classes. LCA models were run adding one class at a time until the model statistics showed that adding more classes would likely not improve the model anymore [44, 52]. All model statistics for the male and female LCAs are presented in Table 2.

\section{Results}

\section{Gender Differences in Background Characteristics and Exposure to Potential Risk Factors}

Separate chi-square tests showed that there were both gender differences and similarities. Men in the sample were significantly more likely than the women to report a first offense prior to 18 years of age, a current violent offense, early first drug use, the use of (soft and/or hard) drugs prior to incarceration, and psychological treatment prior to incarceration. Women were significantly more likely than men to be incarcerated for a drug offense, to have a child and to be unemployed, in debt, and in any type of relationship (minimum of 3 months) prior to incarceration (see Table 1 for percentages and statistics). In addition, the results showed no significant gender differences for the variables property offense, runaway, parental deviance, homelessness, and state benefits.

\footnotetext{
${ }^{5}$ Person-centered analyses investigate clusters of individuals, as opposed to variable-centered analyses, which examine relationships between variables.
} 
Table 1 Overview of included variables in latent class analyses with male and female percentages per parameter and chi-square testing

\begin{tabular}{|c|c|c|c|c|}
\hline Variables & $\begin{array}{l}\% \text { Males } \\
(N=1904)\end{array}$ & $\begin{array}{l}\% \text { Females } \\
(N=397)\end{array}$ & $\begin{array}{l}\text { OR } \\
(1=\text { women })\end{array}$ & $X^{2}$ value \\
\hline Early starter (first offense prior $18=1$ ) & 64.7 & 22.3 & 0.16 & $239.97 * *$ \\
\hline Current offense $=$ property offense & 30.7 & 26.7 & 0.82 & 2.53 \\
\hline Current offense $=$ violent offense & 45.7 & 16.6 & 0.24 & $115.03 * *$ \\
\hline Current offense $=$ drug offense & 12.3 & 31.7 & 3.30 & $93.43 * *$ \\
\hline Ran away from home prior 16 & 30.6 & 32.6 & 1.10 & 0.63 \\
\hline Parental deviance (at $12-16$ years) & 34.6 & 31.2 & 0.96 & 0.11 \\
\hline First-time drug use prior 16 & 47.3 & 36.4 & 0.64 & $15.37 * *$ \\
\hline Soft drugs use in 12 months prior arrest & 47.3 & 30.9 & 0.50 & $35.86^{* *}$ \\
\hline Hard drug use in 12 months prior arrest & 32.1 & 21.4 & 0.57 & $18.13^{* *}$ \\
\hline Homeless at the time of arrest & 6.9 & 6.2 & 0.89 & 0.29 \\
\hline $\begin{array}{l}\text { Psychological treatment in } 12 \text { months } \\
\text { prior arrest }\end{array}$ & 36.3 & 26.0 & 0.62 & $14.59 * *$ \\
\hline Children (regardless of daily care) & 45.5 & 65.4 & 2.26 & $50.53 * *$ \\
\hline Unemployed at time of arrest & 40.1 & 46.4 & 1.29 & $5.31 *$ \\
\hline Receiving state benefits at time of arrest & 35.2 & 39.4 & 1.20 & 2.44 \\
\hline Debts & 57.0 & 68.5 & 1.64 & $17.58 * *$ \\
\hline $\begin{array}{l}\text { Any type of romantic relationship } \\
\text { (minimum of } 3 \text { months) }\end{array}$ & 50.2 & 61.0 & 1.56 & $15.19 * *$ \\
\hline
\end{tabular}

$* p<.05, * * p<.01$

\section{Male Latent Classes}

For the male data, the overall model statistics significantly improve with each class, which could be due to the large male sample size. ${ }^{6}$ However, the entropy was highest for the four- and five-class models (respectively, 0.88 and 0.87 ), suggesting that these models fit the data best. Because the four-class model was less reliable, possibly due to model nonidentification, the five-class model seemed a better choice. In combination with the extent to which the model's classes could be meaningfully interpreted, the fiveclass model seemed to provide the most meaningful and distinctive classes. All test statistics for each of the models are presented in Table 2. Classification probabilities were high for all five classes: 0.959 for class 3, 0.912 for classes 1 and 2, 0.911 for class 5 , and 0.894 for class 4 ; this indicated that the probabilities that respondents were being classified in the right class were high.

Table 3 presents the conditional probabilities - or proportion of respondents with a score of 1 (yes) - for each of the 16 variables across the five classes [44]. Conditional

\footnotetext{
${ }^{6}$ Additionally, both the Vuong-Lo-Mendell-Rubin Likelihood Ratio Test (VLMR-LRT) and the Parametric Bootstrapped Likelihood Ratio Test (BLRT) continued to show a significant improvement when testing the $k$ class model with the $k$-1 model up until the model with seven classes. In the seven-class model, the VLMRLRT $p$ value started to show a slight decrease in significance for the first time.
} 
Table 2 Model fit statistics for male and female latent class analyses

\begin{tabular}{|c|c|c|c|c|c|c|c|}
\hline $\begin{array}{l}\text { Number of latent } \\
\text { classes }\end{array}$ & LL & AIC & BIC & $\begin{array}{l}\text { Sample } \\
\text { size-adjusted } \\
\text { BIC }\end{array}$ & $\begin{array}{l}\text { VLMR-LRT } \\
p \text { value }\end{array}$ & $\begin{array}{l}\text { BLRT } \\
p \text { value }\end{array}$ & Entropy \\
\hline
\end{tabular}

\begin{tabular}{|c|c|c|c|c|c|c|c|}
\hline \multicolumn{8}{|c|}{ Males $(N=1904)$} \\
\hline One & $-18,492.9$ & $37,017.9$ & $37,106.7$ & $37,055.9$ & NA & NA & NA \\
\hline Two & $-17,716.3$ & $35,498.6$ & $35,681.8$ & $35,576.9$ & .0000 & .0000 & 0.67 \\
\hline Three & $-17,253.8$ & $34,607.7$ & $34,885.3$ & $34,726.4$ & .0000 & .0000 & 0.82 \\
\hline Four $^{\mathrm{a}}$ & $-17,007.8$ & $34,149.5$ & $34,521.5$ & $34,308.7$ & .0000 & .0000 & 0.88 \\
\hline Five & $-16,813.2$ & $33,794.4$ & $34,260.7$ & $33,993.9$ & .0000 & .0000 & 0.87 \\
\hline Six & $-16,696.3$ & $33,594.6$ & $34,155.3$ & $33,834.4$ & .0000 & .0000 & 0.84 \\
\hline Seven & $-16,622.4$ & $33,480.8$ & $34,135.9$ & $33,761.0$ & .0022 & .0000 & 0.83 \\
\hline \multicolumn{8}{|c|}{ Females $(N=397)$} \\
\hline One & -3622.1 & 7276.2 & 7339.9 & 7289.1 & NA & NA & NA \\
\hline Two & -3406.6 & 6879.2 & 7010.7 & 6906.0 & .0000 & .0000 & 0.78 \\
\hline Three & -3339.0 & 6778.0 & 6977.2 & 6818.6 & .0000 & .0000 & 0.87 \\
\hline Four & -3296.7 & 6727.5 & 6994.4 & 6781.8 & .0077 & .0000 & 0.87 \\
\hline Five & -3268.8 & 6705.6 & 7040.3 & 6773.8 & .3814 & .0000 & 0.84 \\
\hline
\end{tabular}

$L L \log$ likelihood, AIC Akaike information criterion, BIC Bayesian information criterion, LMR-LRT VuongLo-Mendell-Rubin likelihood ratio test (TECH11), BLRT parametric bootstrapped likelihood ratio test (TECH14)

${ }^{a}$ The output of the four-class model produced a warning concerning potential untrustworthiness of some of the model parameters, which could indicate model nonidentification (even after increasing the starting values). However, this problem did not arise in any of the other male (or female) models

probabilities of 0.5 or higher were used to define the separate classes, as this implies that the likelihood of score 1 (yes) is higher than the likelihood of score 0 (no). In addition, for the variable early starter, very low probabilities were interpreted as high probabilities for a later age of onset.

The first class in the final model comprised 362 men (19.0\%) and can be characterized as a subgroup of multi-problem property offenders. These men had the highest probability of offending prior to age 18 and were mainly detained for property offenses. In addition, this group was characterized by a combination of substance abuse, mental health problems, and economic marginalization. They started using drugs prior to age 16 and reported both soft and hard drug uses in the year prior to arrest. They had likely been in mental health treatment prior to arrest and were unemployed, were in debt, and received state benefits as an income source. The second subgroup of 549 males $(28.8 \%)$ can be described as multi-problem violent offenders. Compared to the class 1 men, these men were mainly incarcerated for violent offenses and had higher probabilities of having experienced parental deviancy prior to age 16 and of having run away from home prior to age 16 . They were also likely to have started offending and to have started using drugs at an early age. However, these men mainly reported soft drug use in the year prior to arrest and had a lower likelihood of using hard drugs. Although mental health issues also characterized this group of men, their economic marginalization only comprised debts (as opposed to the additional unemployment and 
Table 3 Conditional probabilities — or proportion of respondents with a score of 1 (yes) - for each of the 12 variables across the separate classes for both the male and female final models

\begin{tabular}{|c|c|c|c|c|c|c|c|c|c|}
\hline \multirow[t]{3}{*}{ Variables } & \multicolumn{5}{|c|}{ Male classes $(N=1904)$} & \multicolumn{4}{|c|}{ Female classes $(N=397)$} \\
\hline & 1 & 2 & 3 & 4 & 5 & 1 & 2 & 3 & 4 \\
\hline & MP-PO & MP-VO & DO & LOW-P & LOW-V & MP-VO & LOW & MP-PO & DO \\
\hline Early starter & 0.773 & 0.717 & 0.567 & 0.746 & 0.478 & 0.556 & 0.064 & 0.422 & 0.077 \\
\hline Property offense & 0.978 & 0.000 & 0.000 & 0.976 & 0.000 & 0.000 & 0.348 & 0.795 & 0.000 \\
\hline Violent offense & 0.000 & 0.858 & 0.000 & 0.000 & 0.782 & 0.440 & 0.240 & 0.000 & 0.000 \\
\hline Drug offense & 0.000 & 0.000 & 0.959 & 0.000 & 0.000 & 0.203 & 0.000 & 0.000 & 1.000 \\
\hline Ran away & 0.494 & 0.513 & 0.208 & 0.097 & 0.078 & 0.701 & 0.150 & 0.588 & 0.129 \\
\hline Parental deviance & 0.455 & 0.504 & 0.245 & 0.228 & 0.201 & 0.556 & 0.222 & 0.427 & 0.286 \\
\hline Early drug use & 0.740 & 0.781 & 0.368 & 0.217 & 0.122 & 0.842 & 0.145 & 0.660 & 0.128 \\
\hline Soft drugs & 0.681 & 0.766 & 0.378 & 0.245 & 0.172 & 0.744 & 0.059 & 0.524 & 0.202 \\
\hline Hard drug & 0.674 & 0.428 & 0.325 & 0.016 & 0.092 & 0.454 & 0.015 & 0.595 & 0.062 \\
\hline Homeless & 0.171 & 0.073 & 0.048 & 0.019 & 0.024 & 0.093 & 0.000 & 0.233 & 0.009 \\
\hline Mental health problems & 0.605 & 0.520 & 0.209 & 0.125 & 0.188 & 0.278 & 0.199 & 0.590 & 0.110 \\
\hline Children & 0.469 & 0.371 & 0.535 & 0.460 & 0.489 & 0.427 & 0.657 & 0.645 & 0.805 \\
\hline Unemployed & 0.613 & 0.438 & 0.394 & 0.372 & 0.224 & 0.527 & 0.353 & 0.670 & 0.430 \\
\hline State benefits & 0.503 & 0.466 & 0.307 & 0.189 & 0.218 & 0.410 & 0.331 & 0.610 & 0.326 \\
\hline Debts & 0.776 & 0.620 & 0.521 & 0.420 & 0.454 & 0.848 & 0.588 & 0.824 & 0.611 \\
\hline Relationship & 0.394 & 0.389 & 0.610 & 0.603 & 0.601 & 0.579 & 0.643 & 0.657 & 0.559 \\
\hline$N$ & 362 & 549 & 235 & 223 & 535 & 73 & 149 & 65 & 110 \\
\hline
\end{tabular}

$M P-P O$ multi-problem property offenders, $M P-V O$ multi-problem violent offenders, $D O$ drug-connected offenders, $L O W-P$ early-starting low-risk property offenders, $L O W-V$ late-starting low-risk violent offenders, $L O W$ low-risk exposure

state benefits among class 1 men). The third class of men $(235 ; 12.3 \%)$ can be labeled as drug-connected offenders. They were officially early starters, but with a lower probability than class 1 and class 2 and were mainly incarcerated for a drug-related offense. Overall, these men reported low-risk exposure, except for the variable debts. Additionally, this group was the only male class that was characterized by having children; they also reported being in a relationship prior to arrest. The fourth class of 223 men $(11.7 \%)$ could be characterized as a group of early-starting property offenders with a lack of risk exposure, as they had low probabilities on all other variables except on the variable relationship. The fifth and final class $(535 ; 28.1 \%)$ was the only late-starting subgroup of male offenders. They were mainly detained for violent offences and resembled class 4 men for their lack of risk exposure and having a relationship prior to arrest.

\section{Female Latent Classes}

Based on the standard model statistics, the three-class model appeared to have the best values at first sight, as this model had both the highest entropy and improved statistics across the board as compared to the two-class model: higher log 
likelihood and lower values on the AIC, on the Bayesian information criterion (BIC), and on the sample size-adjusted BIC. However, even though the BIC started increasing again in the four-class model as compared to the three-class model, all other statistics continued to improve. ${ }^{7}$ In the five-class model, the entropy decreased, while the BIC further increased. Thus, although the model statistics did not give a single solution that best fits the female data, the four-class model seemed to have the most meaningful and distinctive classes, when compared to the three- and five-class models. All test statistics for each of the models are presented in Table 2. Classification probabilities were high for all four classes: 0.982 for class 4, 0.925 for class 3, 0.920 for class 2, and 0.869 for class 1 .

Table 3 presents the conditional probabilities - or proportion of respondents with a score of 1 (yes) - for each of the 16 variables across the four classes [44]. The women in class 1 represent $18.4 \%$ of the total sample $(n=73)$ and can be described as a group of multi-problem violent offenders. This group had the highest probability for first-time offending before the age of 18 and loaded highest on current violent offense as compared to the other classes (although not reaching the 0.5 level). Growing up with deviant parents and running away from home prior to age 16 further characterized these women. They were likely to have started drug use prior to age 16 and were most likely to have reported soft drug use in the year prior to arrest. Furthermore, their lives prior to incarceration were characterized by unemployment and debts. Like the women in all four classes, the class 1 women had a high probability of being in a relationship prior to incarceration. Class 2 was the largest with 149 members $(37.5 \%)$ and was characterized by late-starting women with low-risk exposure. This group only had higher probabilities on the factors children and debts. However, the fact that these group members did not load on any of the other risk factors also implies that we know little about the reasons why these women ended up incarcerated. Class 3 was the smallest with 65 members $(16.4 \%)$, and we refer to this group as multi-problem property offenders. Almost all of these women were incarcerated for a property offense. The lives of these women were characterized by a multitude of problems covering several broad domains. They reported parental deviance and running away from home when growing up, early first drug use, both soft and hard drug uses in the year prior to their arrest (as opposed to the class 1 women who mainly used soft drugs), and by treatment for mental health problems. The women in class 3 were also economically marginalized as shown by the high proportion of women who were unemployed, had debts, and received state benefits prior to their arrest. Finally, class 4 consisted of 110 women $(27.7 \%)$ and was labeled as drug-connected women as all of the class members were incarcerated for a drug offense. Furthermore, this class had the highest percentage of women with children and was also characterized by debts (although with a lower probability compared to classes 1 and 3 ). Therefore, apart from their type of offense, these women highly resembled the class 2 women concerning a low exposure to known risk factors for offending.

\footnotetext{
${ }^{7}$ In addition, the VLMR-LRT and the BLRT both showed a significant improvement comparing the threeclass model with the four-class model. The VLMR-LRT test no longer showed a significant improvement in the model comparing the four-class model with the five-class model.
} 


\section{Discussion}

In the current study, we investigated gender differences in the life experiences of male and female prisoners in The Netherlands. More importantly, we investigated if these life experiences would translate into gendered pathways into prison by conducting LCAs that included a number of different risk factors. We found substantial overlap between the male and female subgroups of inmates when examining the classes that were extracted by the LCAs. Results showed four classes that were similar for both men and women namely the following: (a) a group of multi-problem property offenders, (b) a group of multi-problem violent offenders, (c) a group of drug-connected offenders, and (d) a group of offenders with low-risk exposure. For the first three groups, not only did the labels overlap but so did also a number of the characteristics that defined the male and female classes. Both male and female multi-problem property offenders are characterized by early and current drug use (soft- and hard drugs), mental health problems, unemployment, state benefits, and debts. Across gender, the multi-problem violent offenders have higher probabilities of being early starters, of having run away from home, and of exposure to parental deviance, debts, early drug use, and current soft but not hard drugs. For both incarcerated men and women, being a drug-connected offender implies the highest probability of having children (compared to the other classes) and of having debts and relationships prior arrest.

It is difficult to equate the current results with the existing empirical work, as few scholars have been able to compare data on male and female prisoners that were collected with similar methods. Daly [16] is one of the few scholars who describe both adult male and female subgroups - albeit qualitatively - based on similar risk factors and background characteristics as employed in the current study. Comparing the male subgroups to Daly's descriptions, there appears to be some overlap for the group of multi-problem violent offenders with Daly's harmed-and-harming men. In line with the characteristics of the current group of multi-problem violent offenders, her qualitative description includes deviant parents in childhood and current violent behavior and drug abuse as a way to cope with life. There also seems to be some overlap between the multi-problem property offenders and Daly's street men concerning the drug abuse and economic struggles leading to (property) offending. However, our current multiproblem property offenders also show clear mental health problems, which are not featured in Daly's description of both the standard and the hardened street men. Conversely, Daggett's [14] description of street men does include a history of mental health problems.

Although both Daly [16] and Daggett [14] described a class of drug-connected men, our group of drug-related offenders does not show high probabilities for any drug use as was the case for Daly's drug-connected typology. However, given the differences in drug laws between The Netherlands and most Anglo-Saxon jurisdictions, some divergence is to be expected. In The Netherlands, drug use in itself is not an offense. Therefore, the drug offenses that led to the incarceration are more likely related to drug trafficking, drug dealing, and/or the production of drugs. Last, we did not find a subgroup comparable to Daly's category of the costs and excesses of masculinity. Although we did find a low-risk-exposure group of violent offenders, we did not include a measure of alcohol abuse that characterizes the typology of explosively violent men (i.e., one of the subcategories of costs and excesses of masculinity). 
Examining the female typologies in the context of Daly's [16] seminal work, the current study shows comparable classes for her street women (multi-problem property offenders), harmed-and-harming women (multi-problem violent offenders), and drugconnected women. However, our current results did not support a separate subgroup of battered women. As all the female classes are characterized by relationships, and we did not include a measure of relationship quality or partner violence, we cannot determine whether the female low-risk-exposure offenders were, in fact (partially), made up of battered women. Besides Daly's work, the current results also align reasonably well with a recent LCA of female prisoners in Ohio. In her study, Brushett [7] also described a low-risk class and two separate classes resembling Daly's street and harmed-and-harming women. Daggett's [14] analyses also show a distinct typology of street women that appears to overlap somewhat with both of the current female multi-problem typologies (i.e., property and violent) concerning background characteristics, such as parental substance abuse, history of drug use, and mental health problems. Nevertheless, Daggett's street women are mainly incarcerated for drug-related offenses as opposed to the violent or property offenses that characterize the two female multi-problem typologies in the current study.

Despite the substantial overlap between male and female classes, some gender differences did appear. For the men, the low-risk-exposure offenders consist of two separate groups, namely low-risk property offenders and low-risk violent offenders. But for women, it appears that the low-risk-exposure group is not characterized by either property or violent offenses. It is possible that these women are incarcerated for other offenses such as unpaid fines (see [31]). Further, while four out of five male classes are characterized as early starters, this is only the case for one of the female classes (i.e., multi-problem violent offenders). It is also striking that all the female classes can be characterized by debts and relationships, while this is the case for only three out of five (different) male classes. Whereas only one male class loads high on the variable children, this is the case for three out of four female classes. The female multiproblem property offenders are also characterized by running away from home as are the male and female multi-problem violent offenders. This seems to be in line exclusively with Daly's [16] description of street women. Finally, there are also notable gender differences in the sizes of the different classes. Although percentages are difficult to compare when the total number of classes differs, it is clear that for the men, the largest group is that of the multi-problem violent offenders, while for the women, the low-risk class forms the largest subgroup. Furthermore, the group of drugconnected offenders seems substantially larger among the women than is the case for the men (i.e., 12 versus $28 \%$ ).

Concerning the prevalence of potential risk factors, male inmates were more likely to be early starters and more often incarcerated for a violent offense when compared to the female inmates. Furthermore, consistent with other studies [33], we found that a significantly higher percentage of men than women were early first-time drug users (both soft and hard drug uses). The men also reported having received mental health treatment prior to incarceration more often than the female inmates. This finding is somewhat unexpected in light of the existing literature. Studies investigating the prevalence of mental health problems do find higher prevalence rates for mental health problems among women, mainly concerning trauma-related symptoms (e.g., [12, 25, 41]). This seeming incongruity could be due to the difference between experiencing 
symptoms and seeking treatment for experienced symptoms. For example, Drapalski et al. [19] did not find gender differences in pre-prison treatment-seeking behavior among male and female inmates. However, during incarceration, women were twice as likely to seek and receive jail-based mental health treatment than men. This finding could signal substantial undiagnosed and/or untreated mental health difficulties among female prisoners prior their incarceration. Furthermore, conditions such as antisocial personality disorder are more prevalent among male than female prisoners (e.g., [12, 19]) and, due to the externalizing nature of its symptoms (i.e., offending), could more often lead to (forced) psychiatric or forensic treatment. This in turn could lead to higher rates of pre-imprisonment mental health treatment among male compared to female inmates.

No significant gender differences were found in the experiences of parental deviance in childhood, running away from home, being homeless or receiving state benefits as an income source. Concerning parental deviance, our findings seem in line with a recent meta-analysis on the effect of parental incarceration on antisocial behavior in children, which showed that parental incarceration increases the chances for antisocial behavior among both boys and girls [49]. In addition, a recent study on male and female federal prisoners showed similar rates across gender for parental history of drug and alcohol abuse as well as parental criminal activity [14]. However, other American studies seem to find inconsistent results regarding the effects of parental deviance. Some suggest that parental deviance is more often found in the backgrounds of female offenders than male offenders [54] whereas others find that it has a more pronounced effect on boys than girls [66]. These findings may be incongruent with our results because our measure of parental deviance is a composite variable consisting of different combinations of parental substance abuse, parental convictions, and/or parental incarceration.

With regard to running away from home, American studies have reported that, in general, the amount of boys and girls that run away from home is more or less equal (e.g., [26, 34]). However, a previous Dutch study did find gender differences among boys and girls in residential treatment; girls were significantly more likely to report running away prior to institutionalization than boys [32], which could be specific to such high-risk juvenile groups. Although the existing empirical evidence is not conclusive, running away from home has been found to predict later offending across gender [29]. Nevertheless, gender differences may still lie within the motivations to run away from home; where girls seem to be more often pushed out (i.e., escape from abusive home), boys seem more likely to be pulled out (i.e., gang involvement; [35]).

\section{Limitations}

While our findings make a substantial contribution to the growing body of scholarship on gendered pathways to offending, they are limited in some respects. Child abuse is prominently featured in much of the work on female pathways to offending. Although child abuse was measured in the VIP study, comparable data on the male prisoners was lacking. This prevented us from being able to include child abuse in the LCAs. However, because child abuse and running away from home are strongly correlated (e.g., $[20,42,45])$, we feel that our measure of running away may capture experiences of childhood abuse. Furthermore, in the current study, we did not include a measure of relationship quality or of partner violence victimization and perpetration. While 
previous studies have shown that both partner violence victimization and perpetration occur regardless of gender (e.g., [8, 31]), men inflict more serious injuries than women during partner violence [59]. In this regard, it is noteworthy that we found a distinctive class of men (class 5) who were late starters, convicted of violent crimes, involved in relationships, and had a low level of risk factors. It could be that these men are, in fact, imprisoned for domestic violence.

Finally, although most of the variables in the study were measured identically across the male and female samples, this was not the case for our measures of current offense. We used self-reported data for the women and official data for the men. On the one hand, there is a possibility that inaccurate self-reports among the female prisoners could have produced less reliability in the current offense variables. On the other hand, most incarcerated women will at least know the reason for their current incarceration even if they are less sanguine about prior periods of incarceration. As the women were asked for the official reason that they were currently incarcerated (regardless of their own plea and/or perception), we do not expect the self-report data to be affected by a reluctance to admit to any committed offenses. We also acknowledge the between-study variation in the selection of participants. Where all male participants were in pre-trial detention, two thirds of the female sample had already been convicted. As official criminal records were missing for the VIP sample, we had no information on how long each of the female participants had been incarcerated.

\section{Implications and Conclusion}

The discussion of gender similarities and differences in typologies and risk factors that characterize pathways to prison has important implications for our conceptualization of gendered lives. In addition to the concepts of gendered pathways and gendered crime, Daly [17] formulated the concept of gendered lives by referring to the ways in which the daily lives of men and woman are organized by gender, shaping identities, and providing opportunities for (criminal) actions and behavior. However, gendered lives can encompass both gendered pathways and gendered crime. As formulated by Kruttschnitt [36]), "gendered lives shape women's pathways into and out of offending and they have a substantial influence on the nature and extent of female offending (or gendered crime)" (p. 302). This suggests that even in the context of seemingly similar pathways to crime, the gendered lives of women and men may be linked to differences in the timing and the fallout from exposure to various risk factors. For example, the experience of early and current soft and hard drug uses for women might be complicated by experiences with prostitution and associated physical and/or sexual victimization (e.g., $[15,46])$. Additionally, as compared to the male multi-problem violent offenders, the lives of the women in the similar female typology could be complicated by potentially dysfunctional and/or violent partner relationships (e.g., see the description of the harmedand-harming typology in [57]). We know from previous research that while serious relationships decrease the risk of adult incarceration among high-risk juveniles, regardless of gender, the context in which these serious relationships were experienced was characterized by violent victimizations only for the female juveniles [32]. Furthermore, the experience of relationships could also be gendered for the typologies of male and female drug-connected offenders. Where female drug-connected offenders can be persuaded, and in some instances forced, into drug smuggling by their romantic 
partners, this is hardly the case for male drug offenders (e.g., [22]). Therefore, gender may still impact the way in which men and women live through these clustered experiences because the processes through which certain experiences are translated into pathways to offending can be gendered [37]. This implies that future gendered pathway research should continue to incorporate a bifocal lens, equally focused on gender similarities as well as on gender differences.

As for the practical implications of the current results, they seem to suggest that interventions should not be necessarily tailored to gender, but rather to offenders' specific background characteristics. In The Netherlands, a gender-neutral approach is still adhered to by the probation services even though internationally, the calls for gender-responsive treatment in women's prisons are increasing (e.g., [13]). Genderresponsive treatment was originally developed to more adequately respond to the specific interrelated needs of female prisoners regarding victimization, substance abuse, and mental health issues (see also [56]). However, our results suggest that both the male and the female multi-problem subgroups of property and violent offenders are characterized by similar backgrounds including a combination of factors such as parental deviance, running away from home, substance abuse, and mental health problems. This raises the question whether gender-responsive treatment programs should be aimed exclusively at women or whether a focus on psychological treatment of such interrelated risk factors might be equally beneficial for some subgroups of male prisoners. Further, interventions aimed at multi-problem offenders might not be suitable and efficient for the low-risk offenders with minimal exposure to the risk factors that are focused on in such interventions. Adapting interventions and re-integration programs to the specific needs of subgroups of male and female inmates would improve both the impact and cost-effectiveness of such programs. However, these programs should keep in mind the different ways in which gender nuances these overarching gender-neutral typologies, which could be an area for future (qualitative) studies to focus on.

Acknowledgments The Prison Project is financially supported by the University of Leiden, The Netherlands Institute for the Study of Crime and Law Enforcement (NSCR), The Netherlands Organization for Scientific Research (NWO), and Utrecht University. The VIP study was made possible with a grant from NWO's open competition in 2010 and additional funding from the NSCR and A-LAB.

\section{Compliance with Ethical Standards}

Ethical Standards Both the Prison Project and the VIP study design, including interviewer protocols, were approved by the Ethics Committee of the Faculty of Law (CERCO) of the VU University Amsterdam.

\section{References}

1. Beijersbergen, K. A., Dirkzwager, A. J. E., Eichelsheim, V. I., van der Laan, P. H., \& Nieuwbeerta, P. (2015). Procedural justice, anger, and prisoners' misconduct: a longitudinal study. Criminal Justice and Behavior, 42(2), 196-218.

2. Belknap, J., \& Holsinger, K. (2006). The gendered nature of risk factors for delinquency. Feminist Criminology, 1(1), 48-71.

3. Blokland, A., \& van Os, R. (2010). Life span offending trajectories of convicted Dutch women. International Criminal Justice Review, 20(2), 169-187. 
4. Bosick, S. J., Bersani, B. E., \& Farrington, D. P. (2015). Relating clusters of adolescent problems to adult criminal trajectories: a person-centered, prospective approach. Journal of Developmental Life Course Criminology, 1(2), 169-188.

5. Brennan, T., Breitenbach, M., Dieterich, W., Salisbury, E. J., \& Van Voorhis, P. (2012). Women's pathways to serious and habitual crime a person-centered analysis incorporating gender responsive factors. Criminal Justice and Behavior, 39(11), 1481-1508.

6. Bright, C. L., Kohl, P. L., \& Jonson-Reid, M. (2014). Females in the juvenile justice system who are they and how do they fare? Crime \& Delinquency, 60(1), 106-125.

7. Brushett, R. A. (2013). Typologies of female offenders: a latent class analysis using the women's risk needs assessment. Unpublished Doctoral dissertation, University of Cincinnati

8. Carbone-Lopez, K., Rennison, C. M., \& Macmillan, R. (2012). The transcendence of violence across relationships: new methods for understanding men's and women's experiences of intimate partner violence across the life course. Journal of Quantitative Criminology, 28(2), 319-346.

9. Central Bureau of Statistics (2015). Gedetineerden: Geslacht, leeftijd en herkomstgroepering [Prisoners: sex, age, and country of origin]. Retrieved from http://www.statline.cbs.nl.

10. Cernkovich, S., Lanctôt, N., \& Giordano, P. (2008). Predicting adolescent and adult antisocial behavior among adjudicated delinquent females. Crime and Delinquency, 54(1), 3-33.

11. Chauhan, P., \& Widom, C. S. (2012). Childhood maltreatment and illicit drug use in middle adulthood: the role of neighborhood characteristics. Development and Psychopathology, 24(03), 723-738.

12. Coolidge, F. L., Marle, P. D., Van Horn, S. A., \& Segal, D. L. (2011). Clinical syndromes, personality disorders, and neurocognitive differences in male and female inmates. Behavioral Sciences and the Law, 29(5), 741-751.

13. Covington, S. (2002). Helping women recover: creating gender-specific treatment for substance-abusing women and girls in community correctional settings. In S. L. A. Straussner \& S. Brown (Eds.), The handbook of addiction and treatment for women: theory and practice (pp. 21-25).

14. Daggett, D. M. (2014). Pathways to prison and subsequent effects on misconduct and recidivism: gendered reality? (Doctoral dissertation, University of Maryland, College Park). Retrieved from http:// drum.lib.umd.edu/bitstream/handle/1903/15130/Daggett_umd_0117E_14897.pdf;sequence=1

15. Dalla, R. L. (2000). Exposing the "pretty woman" myth: a qualitative examination of the lives of female streetwalking prostitutes. Journal of Sex Research, 37(4), 344-353.

16. Daly, K. (1994). Gender, crime and punishment. New Haven: Yale University Press.

17. Daly, K. (1998). Gender, crime and criminology. In M. Tonry (Ed.), The handbook of crime and punishment (pp. 85-108). Oxford: Oxford University Press.

18. Dirkzwager, A. J. E., \& Nieuwbeerta, P. (2015). Prison Project: codebook and documentation. Leiden/ Amsterdam: Universiteit Leiden/NSCR.

19. Drapalski, A. L., Youman, K., Stuewig, J., \& Tangney, J. (2009). Gender differences in jail inmates' symptoms of mental illness, treatment history and treatment seeking. Criminal Behaviour and Mental Health, 19(3), 193-206.

20. Edinburgh, L., Pape-Blabolil, J., Harpin, S. B., \& Saewyc, E. (2015). Assessing exploitation experiences of girls and boys seen at a child advocacy center. Child Abuse \& Neglect, 46(1), 47-59.

21. Fitzgerald, R., Mazerolle, P., Piquero, A. R., \& Ansara, D. L. (2012). Exploring sex differences among sentenced juvenile offenders in Australia. Justice Quarterly, 29(3), 420-447.

22. Fleetwood, J. (2014). For money and love: women's narratives about becoming mules. In: Drug mules, (pp. 92-118). Palgrave Macmillan: UK

23. Fox, B. H., \& Farrington, D. P. (2012). Creating burglary profiles using latent class analysis. Criminal Justice and Behavior, 39(12), 1582-1611.

24. Francis, B., Soothill, K., \& Fligelstone, R. (2004). Identifying patterns and pathways of offending behaviour: a new approach to typologies of crime. European Journal of Criminology, 1(1), 48-87.

25. Gunter, T. D., Chibnall, J. T., Antoniak, S. K., McCormick, B., \& Black, D. W. (2012). Relative contributions of gender and traumatic life experience to the prediction of mental disorders in a sample of incarcerated offenders. Behavioral Sciences \& the Law, 30(5), 615-630.

26. Hammer, H., Finkelhor, D., \& Sedlak, A. J. (2002). Runaway/thrownaway children: national estimates and characteristics. Human trafficking: data and documents. Paper 20.

27. Huebner, B. M., DeJong, C., \& Cobbina, J. (2010). Women coming home: long-term patterns of recidivism. Justice Quarterly, 27(2), 225-254.

28. Jennings, W. G., Piquero, A. R., \& Reingle, J. M. (2012). On the overlap between victimization and offending: a review of the literature. Aggression and Violent Behavior, 17(1), 16-26. 
29. Johansson, P., \& Kempf-Leonard, K. (2009). A gender-specific pathway to serious, violent, and chronic offending? Exploring Howell's risk factors for serious delinquency. Crime \& Delinquency, 55(2), 216240.

30. Jones, N. J., Brown, S. L., Wanamaker, K. A., \& Greiner, L. E. (2014). A quantitative exploration of gendered pathways to crime in a sample of male and female juvenile offenders. Feminist Criminology, 9(2), 113-136.

31. Joosen, K. J., \& Slotboom, A.-M. (2015). Terugblikken op de aanloop: dynamische voorspellers van criminaliteit en detentie gedurende de levensloop van vrouwelijke gedetineerden in Nederland [The prelude in retrospect: dynamic predictors of offending and incarceration across the life course of female prisoners in The Netherlands].Tijdschrift voor. Criminologie, 57(1), 84-98.

32. Joosen, K. J., Zoutewelle-Terovan, M. V., Slotboom, A.-M., \& van der Geest, V. R. (2015). From juvie to jail: gendered risk and protective factors for adult incarceration among high-risk institutionalized boys and girls in The Netherlands. In C. Kruttschnitt \& C. Bijleveld (Eds.), Women's incarceration: an international perspective (pp. 11-31). New York: Routledge.

33. Jordan, C. E., Clark, J., Pritchard, A., \& Charnigo, R. (2012). Lethal and other serious assaults: disentangling gender and context. Crime \& Delinquency, 58(3), 425-455.

34. Kaufman, J. G., \& Widom, C. S. (1999). Childhood victimization, running away, and delinquency. Journal of Research in Crime and Delinquency, 36(4), 347-370.

35. Kempf-Leonard, K., \& Johansson, P. (2007). Gender and runaways risk factors, delinquency, and juvenile justice experiences. Youth Violence and Juvenile Justice, 5(3), 308-327.

36. Kruttschnitt, C. (2013). Gender and crime. Annual Review of Sociology, 39(1), 291-308.

37. Kruttschnitt, C. (2016). The politics, and place, of gender in research on crime. Criminology, 54(1), 8-29.

38. Kruttschnitt, C., \& Bijleveld, C. (2015). Lives of incarcerated women: an international perspective. London: Routledge.

39. Kruttschnitt, C., \& Gartner, R. (2003). Women's imprisonment. Crime and Justice, 30, 1-81.

40. Lansford, J. E., Miller-Johnson, S., Berlin, L. J., Dodge, K. A., Bates, J. E., \& Pettit, G. S. (2007). Early physical abuse and later violent delinquency: a prospective longitudinal study. Child Maltreatment, 12(3), 233-245.

41. Leigey, M. E., \& Reed, K. L. (2010). A woman's life before serving life: examining the negative preincarceration life events of female life-sentenced inmates. Women \& Criminal Justice, 20(4), 302-322.

42. Lynch, S. M., DeHart, D. D., Belknap, J., \& Green, B. L. (2012). Women's pathways to jail: the roles \& intersections of serious mental illness \& trauma. Washington, DC: US Department of Justice, Bureau of Justice Assistance.

43. Makarios, M., Steiner, B., \& Travis, L. F. (2010). Examining the predictors of recidivism among men and women released from prison in Ohio. Criminal Justice and Behavior, 37(12), 1377-1391.

44. McCutcheon, A. L. (1987). Latent class analysis. Thousand Oaks: Sage.

45. Meltzer, H., Ford, T., Bebbington, P., \& Vostanis, P. (2012). Children who run away from home: risks for suicidal behavior and substance misuse. Journal of Adolescent Health, 51(5), 415-421.

46. Miller, J. (1993). Your life is on the line every night you're on the streets: victimization and resistance among street prostitutes. Humanity and Society, 17(4), 422.

47. Miller, J., \& Mullins, C. W. (2009). Feminist theories of girls' delinquency. In M. A. Zahn (Ed.), The delinquent girl (pp. 30-49). Philadelphia: Temple University Press.

48. Moffitt, T. E., \& Caspi, A. (2001). Childhood predictors differentiate life-course persistent and adolescence-limited antisocial pathways among males and females. Development and Psychopathology, 13, 355-375.

49. Murray, J., Farrington, D. P., \& Sekol, I. (2012). Children's antisocial behavior, mental health, drug use, and educational performance after parental incarceration: a systematic review and meta-analysis. Psychological Bulletin, 138(2), 175-210.

50. Muthén, B. (2001). Latent mixture modelling. In G. A. Marcoulides \& R. A. Schumacker (Eds.), New developments and techniques in structural equation modeling (pp. 1-33). Mahwah: Lawrence Erlbaum.

51. Muthén, L. K., \& Muthén, B. O. (1998-2010). MPlus user's guide (6th ed.). Los Angeles, CA: Author. Available from http://www.statmodel.com

52. Nylund, K. L., Asparouhov, T., \& Muthén, B. O. (2007). Deciding on the number of classes in latent class analysis and growth mixture modeling: a Monte Carlo simulation study. Structural Equation Modeling, 14(4), 535-569.

53. Odgers, C. L., Moffitt, T. E., Broadbent, J. M., Dickson, N., Hancox, R. J., Harrington, H., ... \& Caspi, A. (2008). Female and male antisocial trajectories: from childhood origins to adult outcomes. Development and Psychopathology, 20(2), 673-716. 
54. Payne, B. K., Gainey, R. R., \& Carey, C. S. (2007). All in the family: gender, family crimes, and later criminality. Women \& Criminal Justice, 16(4), 73-89.

55. Salisbury, E. J., Van Voorhis, P., \& Spiropoulos, G. V. (2008). The predictive validity of a genderresponsive needs assessment: an exploratory study. Crime \& Delinquency, 55, 550-585.

56. Saxena, P., Messina, N. P., \& Grella, C. E. (2014). Who benefits from gender-responsive treatment? Accounting for abuse history on longitudinal outcomes for women in prison. Criminal Justice and Behavior, 41(4), 417-432.

57. Simpson, S. S., Yahner, J. L., \& Dugan, L. (2008). Understanding women's pathways to jail: analysing the lives of incarcerated women. The Australian and New Zealand Journal of Criminology, 41(1), 84-108.

58. Slotboom, A.-M., Kruttschnitt, C., Bijleveld, C., \& Menting, B. (2011). Psychological well-being of incarcerated women in The Netherlands: importation or deprivation? Punishment \& Society, 13(2), 176197.

59. Tjaden, P., \& Thoennes, N. (2000). Prevalence and consequences of male-to-female and female-to-male intimate partner violence as measured by the National Violence Against Women Survey. Violence against women, 6(2), 142-161.

60. Van Voorhis, P., Wright, E. M., Salisbury, E., \& Bauman, A. (2010). Women's risk factors and their contributions to existing risk/needs assessment: the current status of a gender-responsive supplement. Criminal Justice and Behavior, 37(3), 261-288.

61. Vaughn, M. G., Newhill, C. E., Litschge, C. M., \& Howard, M. O. (2008). Cluster profiles of residentially incarcerated adolescent females: violence and clinical mental health characteristics. Residential Treatment for Children \& Youth, 24(1-2), 35-53.

62. Vaughn, M. G., Salas-Wright, C. P., Delisi, M., \& Piquero, A. R. (2014). Health associations of druginvolved and criminal-justice-involved adults in the United States. Criminal Justice and Behavior, 41(3), 318-336.

63. Walmsley, R. (2015). World female imprisonment list (3rd ed.).Retrieved from http://www.prisonstudies.org.

64. Wareham, J., Dembo, R., Poythress, N. G., Child, K., \& Schmeidler, J. (2009). A latent class factor approach to identifying subtypes of juvenile diversion youths base on psychopathic features. Behavioral Sciences and the Law, 27(1), 71-95.

65. Wermink, H., Johnson, B. D., de Keijser, J. W., Dirkzwager, A., \& Nieuwbeerta, P. (2016). The influence of detailed offender characteristics on consecutive criminal processing decisions in The Netherlands. Crime \& Delinquency, 1-35. doi: 10.1177/0011128715624929.

66. Wildeman, C. (2010). Paternal incarceration and children's physically aggressive behaviors: evidence from the Fragile Families and Child Wellbeing Study. Social Forces, 89(1), 285-309. 